\title{
Kittens in the Oven: Race Relations, Traumatic Memory, and the Search for Identity in Julia Alvarez's How the García Girls Lost Their Accents
}

Natalie Carter

George Washington University, USA

\begin{abstract}
The search for an ever-elusive home is a thread that runs throughout much literature by authors who have immigrated to the United States. Dominican authors are particularly susceptible to this search for a home because "for many Dominicans, home is synonymous with political and/or economic repression and is all too often a point of departure on a journey of survival" (Bonilla 200). This "journey of survival" is a direct reference to the dictatorship of Rafael Leonidas Trujillo Molina, who controlled the Dominican Republic from 1930-1961. The pain and trauma that Trujillo inflicted upon virtually everyone associated with the Dominican Republic during this era is still heartbreakingly apparent, and perhaps nowhere is that trauma more thoroughly illustrated than in the literature of Julia Alvarez. Alvarez is a prime example of an author who utilizes narrative in a clear attempt to come to grips with lingering traumatic memories. After her father's role in an attempt to overthrow the dictator is revealed, Alvarez's family is forced to flee the Dominican Republic as political exiles, and a sense of displacement has haunted her since. Because both the Dominican Republic and the United States are extraordinary racially charged, concepts of home and identity are inextricably bound to race relations in much of Alvarez's art. Using theoretical concepts drawn from the fields of trauma studies and Black cultural studies, this essay examines Alvarez's debut novel in order to illustrate the myriad ways in which culture, politics, and race converge and speak through each other, largely in the form of traumas that can irreparably alter one's sense of home, voice, and identity.
\end{abstract}

[Keywords: Race Relations; Traumatic Memory; Identity]

In her 1998 essay, "A Vermont Writer from the Dominican Republic," Julia Alvarez relates an interview with an elderly Vermont citizen who tells her, "Just because your cat went and had kittens in the oven, you wouldn't call them biscuits, now would you?" (188). Though it is hard to discern from this anecdote by itself, Alvarez's point in this essay is that in Vermont, she finally feels as though she has found both a community and a home where she "fits." This search for an ever-elusive home - a place where one fits-is a thread that runs throughout the majority of literature by authors who, like Alvarez, have immigrated to the United States. Dominican authors, as Janira Bonilla points out in, "Transnational Consciousness: Negotiating Identity in the Works of Julia Alvarez and Junot Díaz," are particularly susceptible to this search for a home because the word itself "often conjures up the idea of a safe and stable haven embodied by kinship ties, a native language, and culturally specific practices... [However,] for many Dominicans, home is synonymous with political and/or economic repression and is all too often a point of departure on a journey of

Rupkatha Journal on Interdisciplinary Studies in Humanities (ISSN 0975-2935), Vol 2, No 3, 2010

URL of the Issue: http://rupkatha.com/v2n3.php

URL of the article: http://rupkatha.com/V2/n3/kittensintheoven.pdf

(c) www.rupkatha.com 
survival" (200). This "journey of survival" is a direct reference to the dictatorship of Rafael Leonidas Trujillo Molina, who controlled the Dominican Republic from 1930-1961. Trujillo's regime is a particularly dark spot in Dominican history, and under his reign, tens of thousands of people were violently, publicly, and often arbitrarily murdered.

Fifty years after his assassination, the pain and trauma that Trujillo inflicted upon virtually anyone associated with the Dominican Republic during this era is still heartbreakingly apparent, and perhaps nowhere is that trauma more thoroughly illustrated than in the literature of Dominican-born authors like Julia Alvarez. Alvarez is a prime example of an author whose art is a clear attempt to come to grips with lingering traumatic memories. After her father's role in an attempt to overthrow the dictator was revealed, Alvarez's family was forced to flee the Dominican Republic as political exiles, and a sense of displacement has haunted her since ("Vermont"). Because both the Dominican Republic and the United States are extraordinary racially charged, concepts of home and identity are inextricably bound to race relations in much of Alvarez's work. Using an interweaving of theoretical concepts drawn from the fields of trauma studies and black cultural studies, this essay will examine Alvarez's debut novel, How the García Girls Lost Their Accents, in order to illustrate the myriad ways in which culture, politics, and race converge and speak through each other, largely in the form of traumas which can irreparably alter one's sense of home, voice, and identity. Further, an in-depth analysis of the García family's Haitian maid, Chucha, is undertaken in order to demonstrate a pattern that is clearly evolving; that is, through Chucha, one can see the ways that an anti-Haitian construction of the Dominican Republic is inadvertently reified in this text, but one can also identify the ways that this racist construction can be subverted through the use of scriptotherapy.

In Killing Spanish: Literary Essays on Ambivalent U.S. Latino/a Identity, Lyn Di lorio Sandín opens her text with a declarative statement: "The protagonists of contemporary U.S. Latino/a fiction are caught in a bind" (1). This bind, she explains, is that "on the one hand, they face the pressures of assimilation into mainstream American culture. On the other, they are profoundly enmeshed in families closely tied to their communities of origin" (1). Benigno Trigo echoes the dilemma presented by this divide of the national imaginary, and claims that when "Latino authors in the United States write about their experiences as exiles and/or immigrants, they often describe the temporal effects of growing up in a country that is both home and not home to them. They tend to describe contradictory pressures to both forget and return to the past, to both embrace and resist the present" (81). The attempt to find one's voice while negotiating both physical and imaginary space on a multiplicity of borders and margins is not a new concept in the realm of cultural studies; however, it is not one that has been exhausted, either. ${ }^{i}$ There are still several interdisciplinary connections which deserve thoughtful, thorough examinations. For example, one 
of the main research tenets within trauma studies is the formation of identity; specifically, how traumatic events manifest themselves, and thus shape one's identity and affect one's ability to form his/her own voice. Certainly, this is a concept that deserves examination in conjunction with black cultural studies; in fact, as Marta Caminero-Santengelo has astutely pointed out, "the rise of ethnic literary studies, including Latino/a studies, is predicated, it would seem, on the given that groups must be allowed to speak for themselves, and to represent themselves" (73).

Before one can analyze formal and conceptual constructs of home, voice, and identity in a text like How the García Girls Lost Their Accents, it is necessary to first explore a theoretical framework that would facilitate such an examination, beginning with a range of theoretical scholarship on the vast and varied experiences of trauma. In her groundbreaking 1992 text, Trauma and Recovery: The Aftermath of Violence-from Domestic Abuse to Political Terror, Harvard psychiatrist Judith Lewis Herman expounds upon a range of issues related to trauma theory. She begins with the assertion that "to study psychological trauma is to come face to face both with human vulnerability... and with the capacity for evil in human nature. To study psychological trauma means bearing witness to horrible events" (8). Further, Herman claims:

Psychological trauma is an affliction of the powerless. At the moment of trauma, the victim is rendered helpless by overwhelming force... Traumatic events overwhelm the ordinary systems of care that give people a sense of control, connection, and meaning...Traumatic events are extraordinary, not because they occur rarely, but rather because they overwhelm the ordinary human adaptations to life... They confront human beings with the extremities of helplessness and terror. (33)

Trauma \& Recovery, now a staple in the canon of trauma literature, provides a clear and concise analysis of many facets of the conditions of trauma, including causes and motivations; what type of person is likely to become a perpetrator, victim, or perhaps some combination of both; and the steps necessary in the process of therapeutic healing.

Literary trauma cannot be legitimately discussed without some mention of Cathy Caruth, whose monumental 1996 text, Unclaimed Experience: Trauma, Narrative, and History, is arguably the single most important work in the field of trauma theory as it stands today. Caruth's text is rooted in psychoanalysis, and positions Freud as the foundational figure upon which Unclaimed Experience is built. Her goal is to expand the understanding of literature through an analysis of traumatic experience, for "literature, like psychoanalysis," she writes, "is interested in the complex relation between knowing and not knowing" (3). According to Caruth, then, literary language is not meant to be understood on 
just one level. Instead, it is precisely this inherent quality of being simultaneously ambiguous and specific that makes literature worthy of study.

Caruth asserts that, "the term trauma is understood as a wound inflicted not upon the body but upon the mind" (3), and that all traumas have a "moving and sorrowful voice that cries out, a voice that is released...through the wound" (2). This voice, she claims, "witnesses a truth that [the victim] cannot fully know" (3). According to Caruth,

What the parable of the wound and the voice thus tells us, and what is at the heart of Freud's writing on trauma, both in what it says and in the stories it unwittingly tells, is that trauma seems to be much more than a pathology, or the simple illness of a wounded psyche: it is always the story of a wound that cries out, that addresses us in the attempt to tell us of a reality or truth that is not otherwise available. This truth, in its delayed appearance and its belated address, cannot be linked only to what is known, but also to what remains unknown in our very actions and our language. (4)

Though dense at times, a familiarization with Caruth-and especially with Unclaimed Experience - provides indispensable insight when studying a text like How the García Girls Lost Their Accents, which revolves around voice, identity, and "the fraught terrain of speaking for others-the inevitable blind spots, gaps, and silences-which Alvarez, to her credit, nevertheless refuses to shy away from" (Caminero-Santengelo 85).

Herman and Caruth are essential to understanding the foundational theoretical framework of trauma, but in order to gain a richer understanding of the "new literary landscape" (Miller 79) that the García family inhabits, one should also consider Laurie Vickroy's uniquely literary contributions to the field of trauma studies. Vickroy's 2002 text, Trauma and Survival in Contemporary Fiction, provides a lucid examination of the process of narrativization, as well as an extensive discussion of scriptotherapy. Scriptotherapy is Suzette Henke's concept that "writing about trauma can lead toward individual and collective healing and alleviation of symptoms" (qtd in Vickroy 8), which Vickroy adapts to the study of contemporary literature. She writes,

Henke's contention that scriptotherapy offers the possibility of reinventing the self and reconstructing the subject ideologically and reassessing the past pertains well to many fictional narratives that focus on protagonists who attempt to survive by creating enabling stories and self-concepts, thereby recovering a sense of self and agency in the face of devastating losses. My study puts more emphasis on the problematic nature of such constructions....and attempt[s] to enlarge readers' sensitivities to the subtleties of how trauma can be communicated and try to persuade them of the need for social action. (9-10) 
Given that scriptotherapy "makes the characters into writers or creators of some sort, creating correspondence between artistic creation, self-creation [and] imagination is presented as part of a process toward healing, or a way of displacing trauma" (165), it could be argued that the entirety of How the García Girls Lost Their Accents is an act of scriptotherapy for Julia Alvarez. Although the autobiographical nature of this novel has been scrutinized exhaustively by scholars, it should also be noted that the author herself claims the text is a work of fictional autobiography ("Vermont"). As Eda Henao points out, "the question of a person's identity both as an individual and as a member of society continues to be one of the central issues of contemporary Latin American literature" (2); thus, it is plausible to assume that Alvarez's attempt to re-create and re-signify herself through "artistic creation and self-creation" (Vickroy 165) is an attempt to (re)claim an Afro-Latino identity and voice that is uniquely her own.

In "Transnational Consciousness," Bonilla claims that a sense of having a "familiar fixed home is a pivotal component in identity formation. Thus, a geographical point of origin such as one's hometown or country becomes a key marker of identity" (200). As Bonilla points out, this concept is particularly applicable to Dominicans because:

Although some Dominicans may arrive in the United States with the dream of returning to the island, there are many, including second- and thirdgeneration Dominicans, who remain rooted in the United States who are still culturally Dominicans as well as North American. With their ethnic and racial identity under constant assault from the dominant culture, Dominicans may cling to their culture, yet they incorporate many aspects of U.S. culture into it. (200)

This distinction between different generations of immigrants is an immensely important one, and is discussed at length by Ramón Grosfoguel in his text Colonial Subjects. Although Puerto Ricans are the primary subjects of Grosfoguel's interest, in his chapter, "'Coloniality of Power' and Racial Dynamics: Notes Toward a Reinterpretation of Latino Caribbeans in New York City," he includes a discussion of first- and second-generation colonial/racial subjects that is certainly applicable to the García girls. When addressing how the levels of racism that each generation encounters is unique to that generation, and thus shapes the identities of that generation, Grosfoguel makes the argument that historically, America has been falsely portrayed "as the land of opportunity where immigrant groups of all social and racial origins had equal opportunities. In this myth all immigrant groups experienced difficulties in the first generation, but after a few generations were able to become socially mobile" (155). Grosfoguel uses West Indians in New York City during the first half of the twentieth century as an example of non-African subjects who were racialized as African-Americans and thus were subject to the same sorts of discrimination that African-American subjects faced. However, he claims that "post-civil rights transformations of the 
American racial discourses from biological racism to cultural racism made possible ethnic strategies of distinction within the 'black' community" (159), and therefore, in order "to distinguish themselves from the negative symbolic representations of African-Americans, the post-1965 first-generation West Indians emphasized ethnic over racial identity" (159). Essentially, according to Grosfoguel, West Indians were not as badly discriminated against as other racialized groups because they were able to use their accents to accentuate their difference from African Americans. In simplest terms: in this case, sounding white/English was enough to make you not black.

However, as Grosfoguel is quick to point out,

It is important to make the point that second-generation West Indians in New York are a different story. They live, study, and share "colonial" spaces together with African-American youth. Their "accent" is no longer as British Caribbean as that of the first generation of West Indians. They became "African-Americanized" in the "Euro-American" imaginary, suffering similar racial stereotypes and discrimination in public spheres and the labor market. As a result of their African-Americanization, they have been resubsumed as colonial subjects of the U.S. empire. (159)

This concept is implicitly articulated in How the García Girls Lost Their Accents. The title itself is obviously a nod to the girls' (and Alvarez's own) attempts, as Afro-Latinas, to negotiate the murky middle-ground of sounding Spanish enough in English so as to not be identified as African-American, but Anglo enough in Spanish so as to not be discriminated against.

Thus, when both Carla and Sandi García relate having the racist, xenophobic demand, "Go back where you came from, you dirty spic!" (Alvarez $153,171)$ shouted at them, it should be understood that this is an experience that is unique to second-generation immigrants like the García girls for two reasons. First, the racist taunts are not prompted by either their accent or their lack thereof; that is, their mastery of the English language is not in question here-rather, the problem is that the girls play too loud for "La Bruja downstairs" (171) or that Carla is identified as having "monkey legs" (153) by the boys tormenting her." The second reason this comment is unique to the particular situation of secondgeneration immigrants is the reminder that they are not at home in this country, and that "no matter for how long the recipients of such comments have been in the United States, [it] is undergirded by the presumption that Latinos' real homes and proper places are 'there' rather than 'here'" (Caminero-Santengelo 75). Thus, it becomes clear that the García girls' sense of identity is inextricably bound to a sense of home, a home that is being denied to them because of their imposed identification with African-Americans.

At this point, it might be useful to consider the conditions that forced the García family into exile in the first place; that is, the racial, political, and cultural 
perfect storm that sent them to the United States, where "there is no space for fine distinctions of race" (qtd in Mullen 372). The United States' military occupation of the Dominican Republic has been well-documented by numerous historians, for it was this occupation which "set the stage for the rise of the totalitarian regime of Rafael Leonidas Trujillo Molina, who controlled the island from 1930 until his assassination in 1961" (Bonilla 206). Julia Alvarez was born in the Dominican Republic in 1951 and lived there until she was ten, at which point her father's role in a plot to overthrow Trujillo was discovered and the Alvarez family was forced to flee the country as political exiles. Trujillo's dictatorship was unusually cruel, the traumatic memories of which would haunt those who witnessed it for long afterward; thus, it is no surprise that in each section of How the García Girls Lost Their Accents, Alvarez "works in some reminder of the dictator's reign and the violence that was a part of everyday life on the island. This violence is an integral part of the girls' home lives and of their vocabularies even after they have moved to New York" (Barak 164). The novel opens in 1989, twenty-nine years after the García family flees the Dominican Republic, and concludes in 1956, "thirty-three years earlier, in a series of island memories that haunt the García [family] in their U.S. present" (Barak 160). At this point, one should pause to consider how this vocabulary of "violence," "memories," and "haunting" facilitates a useful and necessary juncture into trauma studies.

To illustrate, consider the following passages: “...[Carlos] had lost brothers and friends to the dictator Trujillo. For the rest of his life, he would be haunted by blood in the streets and late night disappearances. Even after all these years, he cringed if a black Volkswagen passed him on the street. He feared anyone in uniform" (146); and:

One night, she let out a yelp to wake up the husband beside her. He sat bolt upright... “¿Qué pasa? ¿Qué pasa? What is wrong?” There was terror in his voice, the same fear she'd heard in the Dominican Republic before they left. They had been watched there; he was followed. They could not talk, of course, though they had whispered to each other in fear at night in the dark bed. Now in America, he was safe, a success even; his Centro de Medicina in the Bronx was thronged with the sick and the homesick yearning to go home again. But in dreams, he went back to those awful days and long nights, and his wife's screams confirmed his secret fear: they had not gotten away after all; the SIM had come for them at last. (139)

These two passages provides a wealth of information to support reading Alvarez's text as a trauma narrative, and taken together, they reveal an incredible amount of insight into the fragile psyche of a Dominican refuge in the United States at this time. 
First, one should consider that, as Bonilla points out in her chapter in Dominican Migration, "even under the best circumstances, immigration is a difficult and often disorienting process. Whether an immigrant leaves his or her home by choice or by force, inevitably something or someone is left behind. Learning a new language and negotiating a new culture is a painful and alienating experience" (205). Obviously, being forced to flee one's homeland with four young children in tow for fear of political assassination does not constitute the "best circumstances." It is also important to note the fact that in the United States, Carlos is surrounded all day by the "sick and the homesick yearning to go home again" (Alvarez 139), a fact which cannot be conducive to good mental health for a recently arrived immigrant. Furthermore, when Carlos awakes with "terror in his voice," it is imperative to recognize that his first words are in Spanish, not English. Thus, by immediately reverting back to his native language when he feels threatened, Carlos is unconsciously revealing that he does not feel safe in his new, white Anglo voice, identity, or country.

At this point, it is helpful to recall the definition of "psychological trauma," due to the fact that in this scene, Carols is close to being a literal embodiment of the term. "Psychological trauma," according to Herman, "is an affliction of the powerless... [that] confronts human beings with the extremities of helplessness and terror" (33). Carlos is obviously powerless before Trujillo, but he is also powerless when dealing with the (white) American government because "although diverse colonized groups may be phenotypically undistinguishable from dominant colonizer groups, they can nevertheless be racialized as inferior others in a colonial situation" (Grosfoguel 155). Herman claims that "traumatic events are extraordinary, not because they occur rarely, but rather because they overwhelm the ordinary human adaptations to life" (33).

After the U.S. government essentially abandon Carlos (after the plot that they hatched to overthrow the dictator that they helped rise to power falls through) Trujillo's henchmen come to his house to question him. Because he cannot say anything without implicating himself in the plot, Carlos spends the entirety of this scene crouched in a closet, "in that suffocating darkness, having to go but not daring to pee in the chamber pot for fear the men might hear a drip in the walls" (Alvarez 216). When contrasted with the "strutting" (24) man that the reader is first introduced to, it seems fair to assume that the stress of this trauma has overwhelmed his ordinary adaptations to life. Furthermore, it also seems fair to assume that this particular traumatic moment is a result of being identified solely as a colonized subject and of subsequently having his voice stripped from him by the (white, Anglo) United States government.

In Trauma \& Recovery, Herman illustrates three main stages of posttraumatic stress disorder: hyperarousal, intrusion, and constriction, and the symptoms of all three manifest themselves in the above quoted passages. Hyperarousal is characterized by poor sleep patterns, as well as a tendency to 
startle easily, both of which Carlos demonstrates when he wakes up in the middle of the night. To be fair, an unexpected yell from the person next to them would startle most anyone; however, most anyone would not wake up with "terror in his voice" (Alvarez 139) and assume that the dictator you had left behind years before in a different country (and who was now dead) had finally come to extract his revenge on you and your family. The third state of post-traumatic stress disorder is constriction, or a state of surrender or shutting down. Carlos reveals symptoms of constriction when he immediately and numbly concludes that Laura's yell must mean that "they had not gotten away after all; the SIM had come for them at last" (139).

However, it is the second state of post-traumatic stress disorder, intrusion, which manifests itself most interestingly in this text. Intrusion is defined as the repeated interruptions of a trauma, which Carlos is certainly experiencing, as revealed by the fact that even "after all these years, he cringed if a black Volkswagen passed him on the street" (139). However, there is another, more subtle way that Alvarez reveals the intrusion of traumatic memory into the lives of the García family: through the structure of the novel itself. Although it is true that the reverse-chronological layout gives the book a level of complexity not present in a strictly chronological narrative, a nonlinear structure also holds additional significance when one interprets the text as a site for exploring the theoretical junctions between trauma theory and black cultural studies, particularly as the field relates to the Dominican Republic. For example, given that "it is as if time stops at the moment of trauma," a traumatic experience will "arrest the course of normal development by its repetitive intrusion into the survivor's life" (Herman 37). The intrusion of traumatic memory is a near-universal symptom of trauma and "appears in the repetitive, intrusive forms of visualizations of the trauma scene" (Caruth 11). Therefore, Alvarez's use of a nonlinear narrative structure to present depictions of life under Trujillo's regime is an ingenious method of representing the disruptive and disjointed nature of the traumatic memory that still exists within those who lived under his rule.

In "Afro-Hispanic and Afro-American Literary Historiography: Comments on Generational Shifts," Edward Mullen claims that "what constitutes being black in racially polarized societies like the United States is very different from perceptions of blackness in Latin America" (372), and perhaps at no other site in How the García Girls Lost Their Accents is this difference more apparent than in Chucha, the García family's Haitian maid in the Dominican Republic. In a relatively minor discussion of the girls' experience in their American grade school, Bonilla states, "the García girls no longer represent an elite Dominican society, but an inferior, filthy, dark, and exotic element that has to be tolerated but not mingled with" (209). Almost unquestionably, the "inferior, filthy, dark, and exotic element" to which Bonilla is implicitly comparing the girls is Chucha. However, before one can address the full implications of Chucha's role in this text, it may 
prove useful to examine the fraught relationship between ("blue-black" [Alvarez 218]) Haitians and ("café-con-leche black" [218]) Dominicans.

In what is arguably the most important footnote he has ever penned, Grosfoguel writes:

Dominicans have more difficulties acknowledging their African heritage than do other Caribbean groups. The nation-building process of the Dominican Republic expelled the African heritage from its' "imagined community." In the context of the "coloniality of power" of the Dominican neocolonial state, "black" is a racial category used to refer to Haitians who are constructed as "savage," "criminal," "lazy," and "opportunist"...This explains why many first-generation Dominican migrants arrived in the United States with a national ideology that denied their "blackness." Thus, many of them suffered a culture shock... when they were called "blacks" by other groups. Second-generation Dominicans have a more positive relationship toward acknowledging their African heritage. However, many of the first-generation Dominicans are still reluctant to associate themselves with African-Americans, Puerto Ricans, and Haitians in the context of New York City. (167)

Silvio Torres-Saillant also addresses the racial tension between Dominicans and Haitians in his text, Caribbean Poetics, noting that that the "Spanish-speaking Caribbean has neglected to acknowledge and/or denied the African component in their culture," despite the fact that like Puerto Rico and Cuba, "80 percent of [the Dominican Republic's] population is black or mulatto" (47). According to Torres-Saillant, the reason for this is to hide "the overwhelming reality of the African presence in the culture" (48). Caribbean Poetics was published in 1997; by the 2000 publication of "The Tribulations of Blackness: Stages in Dominican Racial Identity," Torres-Saillant claims that Dominicans possess a growing awareness of their blackness, and that this awareness is particularly prevalent in those who immigrate to the United States, because they are (often unexpectedly) confronted with two choices: either black or white-neither of which fit into how Dominicans actually view themselves. According to (2000) Torres-Saillant, no longer "can we overlook the social utility of such conceptual openness for Dominicans" (1104). More recently, Ana Celia Zentella has added to the field of Dominican/Haitian scholarship, noting that Dominicans in the United States, "who are predominantly mulattoes, may hold on to Spanish more than other [Latino] groups because Spanish serves to identify them as non-Haitian in the Dominican Republic and as non-African American in the United States" (326). Clearly, this is an area which is ripe for analysis, and looking to How the García Girls Lost Their Accents will help to extend what these scholars are attempting to articulate.

Although Chucha makes her first appearance slightly earlier in the novel, the reader's longest introduction to her occurs via the youngest daughter, Sofía 
(Fifi), in the second section of the chapter entitled, "The Blood of the Conquistadors." Fifi tells the reader:

There was this old lady, Chucha, who had worked in Mami's family forever and who had this face like someone had wrung it out after washing it to try to get some of the black out. I mean, Chucha was super wrinkled and Haitian blue-black, not Dominican café-con-leche black. She was real Haitian too and that's why she couldn't say certain words like the word for parsley or anyone's name that had a $j$ in it, which meant...everyone with nicknames Chucha could pronounce. She was always in a bad moodnot exactly a bad mood, but you couldn't get her to crack a smile or cry or anything. It was like all her emotions were spent, on account of everything she went through in her young years. Way back before Mami was even born, Chucha had just appeared at my grandfather's doorstep one night, begging to be taken in. Turns out it was the night of the massacre when Trujillo had decreed that all black Haitians on our side of the island would be executed by dawn. There's a river the bodies were finally thrown into that supposedly still runs red to this day, fifty years later. Chucha had escaped from some canepickers' camp and was asking for asylum. Papito took her in, poor skinny little thing, and I guess Mamita taught her to cook and iron and clean. Chucha was like a nun who had joined the convent of the de la Torre clan. She never married or went anywhere even on her days off. Instead, she'd close herself up in her room and pray for any de la Torre souls stuck up in purgatory. (Alvarez 218) iii

It seems that even someone not in a Black Cultural Studies seminar would be struck by the reference to Chucha as "Haitian blue-black, not Dominican cafécon-leche black"; in addition to the fact that she is defined solely in opposition to the lighter standard of "café-con-leche," one should also note that in this description, "Haitian" and "Dominican" are used as adjectives, thus directly linking nationality with what is being described (i.e., skin color). However, one should be careful not to fall into the trap of focusing on this one line and ignoring the virtual treasure-trove of evidence that this passage provides for the critical reader examining the connections between race and trauma in How the García Girls Lost Their Accents.

For example, consider the fact that Chucha has "worked in Mami's family forever" and that "Mamita taught her to cook and iron and clean." In her biographical essay, "A White Woman of Color," Alvarez briefly mentions the "dayto-day caretakers [who] were the maids. Most of these women were darkskinned, some of Haitian background. One of them, Misiá, had been spared the machetes of the 1937 massacre when she was taken in and hidden from the prowling guardias by the family" (143). Based on the essentially identical biographical details of the two women, it seems safe to assume that the character of Chucha is based on Misiá. Alvarez concludes this portion of her 
essay by writing, "they told us stories of los santos and el barón del cementerio, of el cuca and las cigupas...These women spread the wings of our imagination and connected us deeply to the land we came from. They were the ones with the stories that had power over us" (143). Despite the rather flowery language, this assertion is tremendously powerful, for in it, Alvarez is making a number of provocative suggestions, both explicitly and implicitly. First, there is the connection between the imaginary, the space of the nation-state, and collective historical memory, which implies "a need to recover a distant self or cultural location through memory" (Mayock 223). Second, Alvarez is suggesting that the Dominican Republic's collective memory and sustentation of language is the project of women-women who occupy the space of caregivers, at that, which suggests that trans-generational storytelling is where the real work and creation of historical memory is located. Furthermore, it should not be overlooked that the women given this task are poor, Haitian women-Haitians, of course, being "the real blacks...who lived next door" ("White" 142), and whose subordinate economic position is implied in their occupation as maids. Intentional or not, these powerful stories provide Chucha, Misiá, and all the other "real black" caregivers a method though which they can participate in an oral culture that is specifically non-Anglo.

The next part of this passage which deserves in-depth analysis is Fifi's declaration that Chucha "was real Haitian too and that's why she couldn't say certain words like the word for parsley or anyone's name that had a $j$ in it, which meant...everyone with nicknames Chucha could pronounce," a statement that is directly related to "the night of the massacre when Trujillo had decreed that all black Haitians on our side of the island would be executed by dawn." The massacre that Fifi is referring to is, of course, the "1937 massacre of 15,000 Haitian immigrants near the border by order of the dictator Trujillo" (TorresSaillant 1092). Although horrific, it is to be somewhat expected that a text (partially) set in the Dominican Republic with a Haitian character would include a reference to this massacre. However, the added detail that Chucha cannot say the word for parsley because she's "real Haitian" is inexplicable-until one realizes that "this detail is itself a reference to the Haitian massacre [and that] the pronunciation of the word parsley was the 'test' given to Haitians to supposedly distinguish them accurately from Dominicans" (Caminero-Santengelo 84). In Why the Cocks Fight: Dominicans, Haitians, and the Struggle for Hispaniola, Michelle Wucker explains how this "test" was administered:

For Haitians...in the streets or in the fields-the soldiers applied a simple test. They would accost any person with dark skin. Holding up sprigs of parsley, Trujillo's men would query their prospective victims: “¿Como se Ilama esto?" What is this thing called? The terrified victim's fate lay in the pronunciation of the answer. Haitians, whose Kreyol uses a wide, flat $r$, find it difficult to pronounce the trilled $r$ in the Spanish word for parsley, 
perejil. If the word came out as the Haitian pe'sil...the victim was condemned to die. (49)

A simple Wikipedia search reveals that the language of Haitian Kreyol is based primarily on 18th Century French, with strong influences from West African and Central African languages, because these were the populations in contact with each other during the development of the language (www.wikipedia.com). Thus, for Afro-Latinos like the García's "real Haitian" maid, Chucha, sounding English is not simply an attempt to distance herself from an African identity and/or identification. Instead, once the significance of the pronunciation of a word like "parsley" is understood, it becomes clear that for a Haitian during Trujillo's dictatorship, sounding "too black" is quite literally a matter of life and death.

The final point that deserves special attention in this passage is Chucha's actual behavior-not just Fifi's perceptions of her. For example, it should definitely be considered that statements like, "all her emotions were spent" and "you couldn't get her to crack a smile or cry or anything" is evidence of Chucha's prolonged state of traumatic constriction, not just a prolonged bad mood like Fifi assumes. In addition to her state of constriction, it also seems safe to assume that Chucha is likely experiencing survivor guilt because she was taken in and protected by the García family, instead of being one of the 15,000 massacred by Trujillo.

Alvarez also presents another, more subversive possibility for Chucha's behavior, one that contradictorily allows for Chucha to negotiate personal space while simultaneously endorsing the anti-Haitian construction of the Dominican Republic. Bonilla points out that "regardless of the fact that Chucha has lived in the Dominican Republic more years than she lived in Haiti...the other Dominican servants fear her because she is Haitian born" (212). This statement recalls Alvarez's earlier-cited anecdote about the kittens in the oven; that is, just because Chucha has immersed herself in Dominican culture, she is still an outsider, and will never be fully accepted by the dominant culture. As has been established, Haitians are the "racialized Other against which Dominicans define their identity" (211), and one of the primary ways that they are Other-ed is through voodoo. Succinctly encapsulating both Torres-Saillant's and Grosfoguel's theses, Bonilla states that "in general, Dominicans tend to define themselves as a Catholic nation of mixed Spanish and Taíno ancestry, indios in opposition to Haitians, who are viewed as black descendents of African slaves who practice voodoo" (212). Via our narrator, Fifi, Alvarez illustrates Chucha's voodoo practice:

Chucha always had a voodoo job going, some spells she was casting or spirit she was courting or enemy she was punishing. I mean, you'd open a closet door, and there, in the corner behind your shoes, would sit a jar of something wicked that you weren't supposed to touch... Mami finally had to give her a room to herself because none of the other maids wanted to 
sleep with her. The maids said she got mounted by spirits. They said she cast spells on them. (219)

What is important in this passage is not the fact that Chucha practices voodoo; instead, it is the way she does it that reveals the subversive nature of her particular practice.

Chucha is aware of the fact that the other maids view her as an inferior, and that she occupies a lower position within the household structure as a result of "her African roots and her status as a Haitian foreigner" (Henao 12). Because she is further aware that "her saviors are also her subjugators" (Bonilla 213), Chucha must use her position as exotic Other to navigate her way within the system that oppresses her. Eda Henao posits that perhaps her "strategy for the manipulation of privilege consists of reinforcing, accepting, and acting out the stereotypes assigned to her...she uses her magic and concoctions in order to consolidate a position of power in relation to the rest of the maids and as a way of manipulating her masters into granting her requests" (13). With this possibility in mind, recall that "Mami finally had to give her a room to herself because none of the other maids wanted to sleep with her" (Alvarez 218) and that "she never married or went anywhere even on her days off. Instead, she'd close herself up in her room" (219). Considering that Chucha is 1) Haitian, 2) a woman, 3) unmarried, and 4) a servant, it is almost unimaginable that she would be able to acquire privacy, a room of her own in a affluent household, a mistress who would leave her in peace, and some sort of sense of autonomy without embracing her position as the "voodoo-soaked Haitian maid" (Hoffman 21) in the García household. As Henao points out: "Through scare tactics derived from her magic and the assertion of her roots, she is able to negotiate some space for herself, thus compensating for her minority status as a black Haitian immigrant woman who is ethnically different from everyone else in the house" (13). Therefore, although Alvarez uses characters like Chucha to "illustrate how Haitians have been historically exploited, mistrusted, and discriminated against" (Bonilla 212), she is also able to demonstrate how colonized subjects can "make a statement, solidify some sense of power, and get herself some room. As such, the markings that identify her as different and which cause her to be discriminated against are turned into weapons against her oppressors" (Henao 13). Chucha creates a space for herself in which she can look African, sound Spanish, and appropriate a uniquely Afro-Latino religious practice-and yet still retains a sense of autonomy. Chucha occupies the lowest position in the collective memory of either nation represented in this text, yet her attempts at scriptotherapymanipulating her position as exotic Other to create a space for herself within the system that oppresses her-is clearly the most successful in this text.

After examining Julia Alvarez's debut novel, How the García Girls Lost Their Accents, through a theoretical lens that combines elements of trauma, race, and cultural studies, it becomes clear that politics, race, and memory can 
333 Kittens in the Oven: Race Relations, Traumatic Memory, and the Search for Identity in Julia Alvarez's How the García Girls Lost Their Accents

converge and speak through each other; furthermore, the ways that they do so can either reinforce existing problems, or they can lead to a new sense of home, voice, and identity for racialized subjects. After reviewing the ways in which a highly racialized figure like Chucha can subversively challenge her social position to carve out a niche for herself, it is hard not to feel a glimmer of hope that there is a positive pattern evolving, and that eventually, Chucha, the García girls, and even Alvarez herself will not be destined to be either kittens or biscuits in the oven. Instead, perhaps they will be kittens or biscuits that occupy spaces where they do not need to be signified at all.

\section{Notes}

'For example, see Gloria E. Anzaldúa's Borderlands/La Frontera: The New Mestiza.

ii The explicitly racist implications of identifying a dark-skinned person as a "monkey" are painfully obvious. For reference, see The Signifying Monkey, or essentially any other piece of scholarship by Henry Louis Gates, Jr.

iii Though lengthy, it is necessary to reproduce this particular passage in its entirety because of the nearly line-by-line analysis that follows.

\section{Bibliography}

Alvarez, Julia. How the Garcia Girls Lost Their Accents. New York: Plume, 1992.

-----. "A Vermont Writer from the Dominican Republic." Something to Declare. Chapel Hill: Algonquin Books, 1998. 187-196.

-----. "A White Woman of Color." Half and Half: Writers on Growing Up Biracial and Bicultural. Ed. Claudine Chiawei O'Hearn. New York: Pantheon Books, 1998. 139-49.

Barak, Julie. "Turning and Turning in the Widening Gyre': A Second Coming into Language in Julia Alvarez's How the Garcia Girls Lost Their Accents." MELUS 23.1 (1998): 159-176.

Bonilla, Janira. "Transnational Consciousness: Negotiating Identity in the Works of Julia Alvarez and Junot Díaz." Dominican Migration: Transnational Perspectives. Eds. Ernesto Sagás and Sintia E. Molina. Gainesville: University Press of Florida, 2004. 200-229.

Caminero-Santengelo, Marta. "Speaking for Others: Problems of Representation in the Writing of Julia Alvarez." On Latinidad: U.S. Latino literature and the Construction of Ethnicity. Gainesville: University of Florida Press, 2007. 73-92.

Caruth, Cathy. Unclaimed Experience: Trauma, Narrative, and History. Baltimore: The Johns Hopkins University Press, 1996.

Grosfoguel, Ramón, with Chloe S. Georas. "Coloniality of Power' and Racial Dynamics: Notes Toward a Reinterpretation of Latino Caribbeans in New York City." Colonial Subjects: Puerto Ricans in a Global Perspective. Berkeley: University of California Press, 2003.

Henao, Eda B. The Colonial Subject's Search for Nation, Culture, and Identity in the Works of Julia Alvarez, Rosario Ferré, and Ana Lydia Vega. Lewiston, NY: The Edwin Mellen Press, 2003.

Herman, Judith. Trauma and Recovery: The Aftermath of Violence-From Domestic Abuse to Political Terror. New York: Basic Books, 1992. 
Hoffman, Joan M. "She Wants to Be Called Yolanda Now': Identity, Language, and the Third Sister in How the García Girls Lost Their Accents." Bilingual Review 23.1 (1998): 21-28.

Mayock, Ellen C. "The Bicultural Construction of Self in Cisneros, Alvarez, and Santiago." Bilingual Review 23.3 (1998): 223-29.

Miller, S. "Caught Between Two Cultures," Newsweek. 119.16 (1992): 78-80.

Mullen, Edward. "Afro-Hispanic and Afro-American Literary Historiography: Comments on Generational Shifts." CLA 38.4 (1995): 371-389.

Romagnolo, Catherine. "Recessive Origins in Julia Alvarez's García Girls: A Feminist Exploration of Narrative Beginnings." Narrative Beginnings: Theories and Practices. Omaha: University of Nebraska Press, 2008. 149-165.

Sandín, Lyn Di lorio. Killing Spanish: Literary Essays on Ambivalent U.S. Latino/a Identity. New York: Palgrave Macmillan, 2004.

Torres-Saillant, Silvio. Caribbean Poetics: Toward an Aesthetic of West Indian Literature. New York: Cambridge University Press, 1997.

-----. "The Tribulations of Blackness: Stages in Dominican Racial Identity." Callaloo 23.3 (2000): 1086-1111.

Trigo, Benigno. "In the Time of Julia Alvarez: Reversing Matricidal Temporalities." Feminist Time Against Nation Time: Gender, Politics, and the Nation-State in an Age of Permanent War. Eds. Victoria Hesford and Lisa Diedrich. Lanham, MD: Lexington Books, 2008. 81-103.

Vickroy, Laurie. Trauma and Survival in Contemporary Fiction. Charlottesville: University of Virginia Press, 2002.

Zentella, Ana Celia. "Latin@ Languages and Identites." Latinos: Remaking America. Eds. Marcelo M. Suarez-Orozco and Mariela M. Páez. Berkeley: University of California Press, 2002. 321-38.

(no author). "Haitian Creole Language." http://en.wikipedia.org/wiki/Haitian_Creole_language. Accessed 06 May 2009.

Natalie Carter is a PhD Candidate at the Department of English, The George Washington University, USA. Email: nlcarter@gwmail.gwu.edu 